\title{
An analysis of present and future seasonal Northern Hemisphere land snow cover simulated by CMIP5 coupled climate models
}

\author{
C. Brutel-Vuilmet, M. Ménégoz, and G. Krinner \\ CNRS and UJF Grenoble 1, Laboratoire de Glaciologie et Géophysique de l'Environnement (LGGE, UMR5183), \\ 38041 Grenoble, France
}

Correspondence to: C. Brutel-Vuilmet (claire.brutel-vuilmet@ujf-grenoble.fr)

Received: 24 July 2012 - Published in The Cryosphere Discuss.: 8 August 2012

Revised: 23 November 2012 - Accepted: 14 December 2012 - Published: 21 January 2013

\begin{abstract}
The 20th century seasonal Northern Hemisphere (NH) land snow cover as simulated by available CMIP5 model output is compared to observations. On average, the models reproduce the observed snow cover extent very well, but the significant trend towards a reduced spring snow cover extent over the 1979-2005 period is underestimated (observed: $(-3.4 \pm 1.1) \%$ per decade; simulated: $(-1.0 \pm 0.3) \%$ per decade). We show that this is linked to the simulated Northern Hemisphere extratropical spring land warming trend over the same period, which is also underestimated, although the models, on average, correctly capture the observed global warming trend. There is a good linear correlation between the extent of hemispheric seasonal spring snow cover and boreal large-scale spring surface air temperature in the models, supported by available observations. This relationship also persists in the future and is independent of the particular anthropogenic climate forcing scenario. Similarly, the simulated linear relationship between the hemispheric seasonal spring snow cover extent and global mean annual mean surface air temperature is stable in time. However, the slope of this relationship is underestimated at present (observed: $(-11.8 \pm 2.7) \%{ }^{\circ} \mathrm{C}^{-1}$; simulated: $\left.(-5.1 \pm 3.0) \%{ }^{\circ} \mathrm{C}^{-1}\right)$ because the trend towards lower snow cover extent is underestimated, while the recent global warming trend is correctly represented.
\end{abstract}

\section{Introduction}

With a maximum extent of about $45 \times 10^{6} \mathrm{~km}^{2}$, seasonal snow cover, essentially located in the Northern Hemisphere (NH) land areas, is the largest component of the terrestrial cryosphere (e.g. Lemke et al., 2007). Snow cover has important effects on climate. The most obvious effect is due to its high albedo. Observational (e.g. Dewey, 1977) and modeling (e.g. Walsh and Ross, 1988; Vavrus, 2007) studies suggest a strong direct influence of snow cover on the overlying lower troposphere, but also on the upper atmosphere (e.g. Alexander et al., 2010). This gives rise to the well-known snow-albedo feedback which (i) is thought to be one important reason for the polar amplification of ongoing and projected climate change (e.g. Groisman et al., 1994; Déry and Brown, 2007). (ii) Hall and Qu (2006) and Fletcher et al. (2012) have shown this feedback to be correctly represented only in a minority of the CMIP3 (Coupled Model Intercomparison Project - Phase 3: http://www-pcmdi.llnl.gov/ ipcc/about_ipcc.php) models. Due to its low heat conductivity, snow also effectively insulates the underlying soil, with important effects on deep soil temperatures and permafrost extent (Zhang, 2005; Lawrence and Slater, 2010; Gouttevin et al., 2012).

These important effects of seasonal snow on climate imply that a correct representation of this variable in currentgeneration climate models is required. Roesch (2006) reported that these models only partly reproduced the pronounced observed decrease of snow cover extent (SCE): observed NH spring snow cover extent decreases by about $0.8 \times 10^{6} \mathrm{~km}^{2}$ per decade since 1970 (Brown and Robinson, 2011). In an analysis of climate projections carried out with these models, Räisänen (2008) reported that the sign of projected changes of seasonal snow water equivalent at the end of the 21 st century with respect to the present is spatially variable because it depends on the present local climate conditions: in very cold regions, climate warming will lead to 
overall increased winter snowfall and thus to a thicker snow cover, while in warmer regions, the higher temperatures will lead to the opposite. However, other snow-related variables, such a SCE, possibly exhibit a more direct relationship to temperature. For example, the observed and simulated nearlinear relationship between Arctic sea ice cover and global mean air temperature on annual time scales, recently reported by Mahlstein and Knutti (2012), allowed these authors to deduce a scenario-independent global mean temperature threshold corresponding to the disappearance of Arctic summer sea ice. This is an interesting relationship because the global annual mean surface air temperature is arguably the most important single metric of the expected future global change, and it is therefore worthwhile to investigate whether a similar relationship exists between NH snow cover extent and global mean temperature.

The fifth phase of the Coupled Model Intercomparison Project (CMIP5; http://cmip-pcmdi.llnl.gov/cmip5/; Taylor et al., 2012), linked to the preparation of the fifth IPCC assessment report, is currently ongoing, running with the most recent versions of more than 30 state-of-the-art coupled climate models and a new set of climate forcing scenarios (van Vuren et al., 2011). It is thus timely to address the following questions: how well do CMIP5 models capture presentday seasonal snow extent and observed recent trends? What are the projected changes of seasonal snow cover in CMIP5 and what determines these changes? How are these linked to global climate change?

The following section will briefly describe the observational data, the model outputs, and the methods used in this study. We then provide a short assessment of the simulated present-day snow cover, including its current trends, and analyze the dominant factors determining the future evolution of Northern Hemisphere spring snow cover as simulated by the CMIP5 models.

\section{Data and methods}

\subsection{CMIP5 output}

In this study we used the simulated monthly snow mass, snow cover fraction, surface air temperature, and solid precipitation fluxes (variable codes: snw, snc, tas, and prsn) from the CMIP5 archive as available on 1 June 2012. Our analysis of seasonal snow cover is restricted to the ice-free land in the Northern Hemisphere (NH-ifl). Unfortunately, the land and ice sheet masks (variable codes sftlf and sftgif) were not available for a substantial number of the CMIP5 models, considerably reducing the number of the models usable in this study (see Table 1). In our analysis, a given grid box is diagnosed to be snow-covered during a given month if the simulated snow mass is above $5 \mathrm{~kg} \mathrm{~m}^{-2}$ in order to ensure a coherent cross-model evaluation of the diagnostic snow cover fraction, which is usually derived from the simulated prog- nostic snow mass. Unless otherwise specified, we present ensemble mean values for the models for which more than one realization of a given experiment (historical or future scenario) is available. The analysis of the climate projections is restricted to the 21 st century except otherwise stated. We use all four basic CMIP5 climate change scenarios RCP2.6, RCP4.5, RCP6.0 and RCP8.5 (Moss et al., 2010; van Vuuren et al., 2011).

\subsection{Observational data}

\subsubsection{Snow cover}

Time series of observed NH-ifl spring snow cover were taken from Brown and Robinson (2012). We furthermore used the spatially distributed monthly SCE dataset produced by the Rutgers University Global Snow Lab (Robinson and Frey, 2000), which we restricted to the period after 1979 because of data inhomogeneity due to different satellite generations (Roesch and Roeckner, 2006).

\subsubsection{Temperature}

The analysis of the relationship between the $\mathrm{NH}$-ifl spring snow cover and global average air temperature was carried out using the HadCRUT4 temperature dataset (Morice et al., 2012). Spatially distributed NH land surface air temperatures from the CRUTEMP4 (Jones et al., 2012) dataset, which were also used in the HadCRUT4 combined landocean dataset, were used for the study of global mean surface air temperature trends and for the analysis of the relationship between the NH-ifl spring snow cover and spring NH-ifl surface air temperatures north of $50^{\circ} \mathrm{N}$.

\subsubsection{Snowfall}

Simulated NH snowfall rates are compared to the spatially distributed WATCH dataset (Weedon et al., 2011) for the 1979-2001 period. The WATCH dataset is essentially based on GPCCv4 (Schneider et al., 2008) precipitation data, but it uses CRU (New et al., 1999, 2000) number of wet days and ERA-40 (Uppala et al., 2005) data for determining the proportion of snowfall to the total precipitation rate.

\subsection{Methods}

\subsubsection{Boreal spring data}

We mainly restricted our analysis of the evolution of $\mathrm{NH}-$ ifl snow cover to the boreal spring because snow cover is most sensitive to temperature during the transition seasons (Brown, 2000) and because long-term snow observations have good spatial and temporal coverage during that time of the year (Brown, 2000; Brown and Robinson, 2011). We thus used average data for the months of March and April. However, the full annual cycle of snow cover is also analyzed. 


\subsubsection{Normalization over the $1986-2005$ reference period}

Data are generally normalized with respect to a 1986-2005 reference period except otherwise stated, 2005 coinciding with the end of the historical CMIP5 runs, the different RCP climate scenarios starting in 2006 (Taylor et al., 2012). Relative snow cover extent (RSCE) is thus defined as the spatially integrated NH-ifl SCE divided by its average spatially integrated value over this reference period for the given months of the year. The same process is used to compute relative snow mass and relative snowfall rates. For a better understanding, these data are generally expressed in percentages. The 1986-2005 period is also used for the temperature. Temperature change is defined with respect to the average value over this reference period for each month.

\subsubsection{Seasonal cycle analysis}

To compare the seasonal cycle of observed and simulated snow cover in a synthetic way, we define, for each grid point, a figure of merit in time $F$ (Hourdin et al., 1999; Krinner et al., 2005) as:

$$
F=\frac{\sum_{i=1}^{12} \min \left(S_{\mathrm{o}, i}, S_{\mathrm{s}, i}\right)}{\sum_{i=1}^{12} \max \left(S_{\mathrm{o}, i}, S_{\mathrm{s}, i}\right)},
$$

where the $S_{\mathrm{o}, i}$ and $S_{\mathrm{s}, i}$ are the observed and simulated climatological monthly snow cover fractions over the 1979-2005 period. A value of 1 indicates a perfect agreement between the simulated and observed monthly snow covers at a given grid point for all climatological months, while a value of 0 indicates that there is no overlap between the time series.

\subsubsection{Snow season length}

The snow season length is evaluated from the annual snow cover fractions. In a given area, a value of 1 indicates that a full snow cover is present during the twelve months of the year in the area; a value of 0.5 is interpreted as a full snow cover that is present during 6 months. It could, in principle, also indicate a $50 \%$ snow cover present all year, or some other distribution yielding an annual average of 0.5 , but the simplest and arguably most reasonable general interpretation remains that of a clear distinction between seasons with and without snow cover. Thus, the snow season length is defined as 12 times the annual mean snow cover fraction.

\subsubsection{Interannual variability}

The interannual variability of NH-ifl spring SCE is evaluated by calculating the $1 \sigma$ standard deviation of a time series obtained by subtracting the 20 -yr running average from the original NH-ifl spring SCE time series. In this way, long- term trends, in particular the anthropogenic warming trend that dominates the signal in the latter period, is filtered out. This time series, devoid of long-term trends, runs from 1932 to 1995 instead of 1922 to 2005 because of the 20 -yr running average, and will be referred to as the high-pass filtered $\mathrm{NH}$-ifl SCE in the following. For each model, the interannual variability is calculated for the first ensemble member only, because calculating the interannual variability from the average of several ensemble members would lead to an erroneously low estimate of the simulated variability.

\subsubsection{Link between SCE and climate variables}

Linear regressions are calculated between NH-ifl SCE and other climate variables, in particular global annual mean surface air temperature and March-April surface air temperature averaged over the ice-free land areas north of $50^{\circ} \mathrm{N}$. The slope of these linear regressions will be called sensitivity of the snow cover extent.

\subsubsection{Uncertainties}

Unless otherwise specified, the reported uncertainties are $1 \sigma$ standard deviations.

\section{Results and discussion}

\subsection{Present}

\subsubsection{Average SCE and trends}

On average, the CMIP5 models tend to reproduce fairly accurately the seasonal cycle of snow cover over the 1979-2005 period over the northern parts of the boreal continents, while there is a slightly stronger misfit in the more southerly regions where snow cover is sparse. This can be seen in Fig. 1, which displays the figures of merit in time $F . F$ is first calculated for each model against the observed Robinson and Frey (2007) snow cover extent, and then the average over all models is taken (Fig. 1a).

The weaker average performance of the climate models in the southern realm of the seasonal snow area is due to incorrect timing of the snow onset and melt, and possibly to an incorrect representation of the annual maximum snow cover fraction. This latter error might be due to the way snow cover extent is diagnosed here: for any given month, snow cover is diagnosed to be complete $(100 \%)$ if the snow mass exceeds a threshold of $5 \mathrm{~kg} \mathrm{~m}^{-2}$, and 0 if the snow mass is below this threshold (see Sect. 2). Figure 2 shows that on average, snow onset tends to be simulated a few days too early, and snow melt about 10-15 days too late in Asia, particularly in the southern part. In North America snow melt tends to occur about 10 days too early. Nonetheless, altogether the seasonal cycle of snow cover tends to be simulated with very good accuracy, and we do not observe a significantly delayed spring 
a)

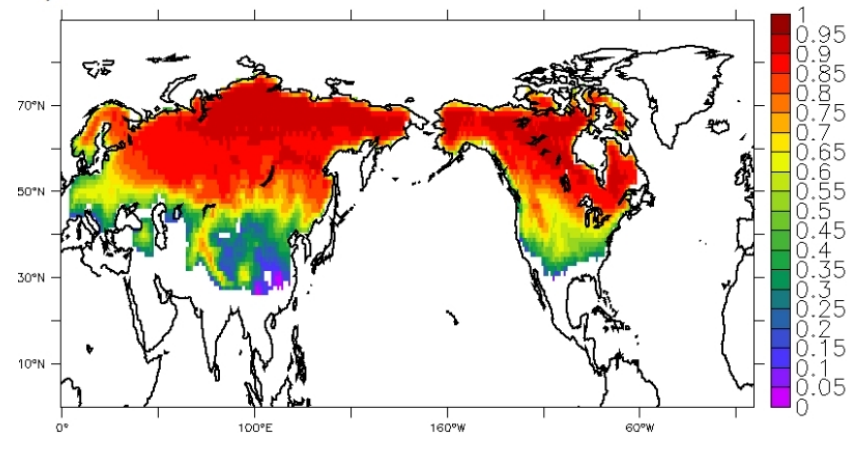

b)

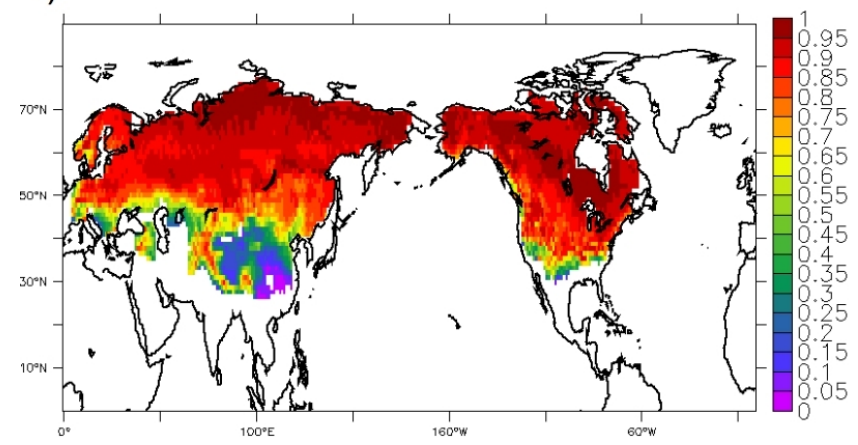

Fig. 1. Agreement $F$ between the simulated and observed climatological seasonal cycles of snow cover for 1979-2005. (a) Average $F$ (mean of $F$ calculated for each individual model); (b) $F$ for the mean model (evaluation of the mean model output).

melt such as reported by Roesch (2006) for the CMIP3 models; however, Brown and Frei (2007) argued that the results by Roesch (2006) were influenced by an erroneous method for estimating snow pack density as a function of snow depth, at least in North America.

The excellent agreement between the simulated multimodel mean and observed average seasonalities of snow cover is coherent with the fact that the multi-model mean snow cover (calculated by averaging the simulated snow covers of all available models) attains a substantially higher score $F$ (shown in Fig. 1b) than the average $F$ of the individual models (Fig. 1a). The "superiority" of the "mean model" in this type of model intercomparison exercise has been clearly shown before for a large range of climate variables (Gleckler et al., 2008) and is therefore no surprise. However, a clear misfit of the "average model" remains over China and Mongolia. This has been reported previously (Roesch, 2006).

There is thus a substantial inter-model dispersion of the simulated snow cover extent around the multi-model average which is, as stated before, close to the observed snow cover extent. This can be clearly seen in Fig. 3 which, for different thresholds (20, 50 and $80 \%)$ and the 1979-2005 period, displays the percentage of models that simulate a frequency of snow cover in March in excess of a given threshold; the southern limit of the area where the probability of observing snow cover in March is higher than this threshold. Broadly, about $50 \%$ of the models tend to simulate March snow cover near the margins of the area of seasonal snow cover in spring too frequently, while the other $50 \%$ of models simulate insufficient snow cover. Substantial inter-model dispersion occurs in flat areas, while in mountain areas, the topography effectively constrains the simulated snow cover. A large overestimate of the spring SCE appears over Tibet, Mongolia and northern China, leading to low values of $F$ in Fig. 1a and b mentioned before.

Although, as just shown, the seasonality of average NH-ifl SCE is fairly well captured by the CMIP5 models, the interannual variability of NH-ifl SCE is clearly underestimated. The $1 \sigma$ standard deviation of the high-pass filtered observed March-April NH-ifl SCE is 5.4\% (the SCE time series were normalized to average 1 for the period 1986-2005 before the high-pass filter was applied). The average model variability is $3.3 \%$. Only the MPI models exhibit a correct interannual variability in excess of $5 \%$. This underestimate of the interannual SCE variability in spring has also been reported by Derksen and Brown (2012).

A substantial and significant trend towards lower NH SCE has been observed over the recent decades (e.g. Dye, 2002; Lemke et al., 2007; Brown and Robinson, 2011). The data provided by Brown and Robinson (2011) yield a negative trend of $(-3.4 \pm 1.1) \%$ per decade for the March and April average RSCE over the 1979-2005 period (Fig. 4). Including not only the period of rapid global warming at the end of the 20th century, the corresponding trend for the 1922-2005 period, equal to $(-1.0 \pm 0.3) \%$ per decade, is clearly weaker. The large majority of the CMIP5 models simulate a negative SCE trend, but all simulate weaker than observed trends, as can be seen in Fig. 4 (trends calculated for the 1979-2005 period). This tendency of the models to underestimate SCE decrease over the most recent decades has already been described for the CMIP3 ensemble (Roesch, 2006) and, in spite of a very good average simulation of the observed snow cover extent over this period (Figs. 1-3), the CMIP5 model ensemble still suffers from this drawback, which appears significant because the average model trend from 1979 to 2005 is $-1.3 \%$ per decade with an inter-model standard deviation of $0.8 \%$ per decade. The positive trends obtained for 2 of the models in Fig. 4 are due to the large interannual variability of the simulated temperature and snow cover in these models. These trends become negative if the linear trends are calculated over a slightly longer period (not shown).

The analysis of all individual realizations (instead of ensemble means) provides very similar conclusions. The average trend of all 113 realizations is identical to that obtained from the ensemble means $(-1.3 \%$ per decade). The simulated SCE trend exceeds the observed trend for only 2 simulations (out of 113 realizations), and it is weaker than $-3.4+1.1=-2.3 \%$ per decade (corresponding to the upper 

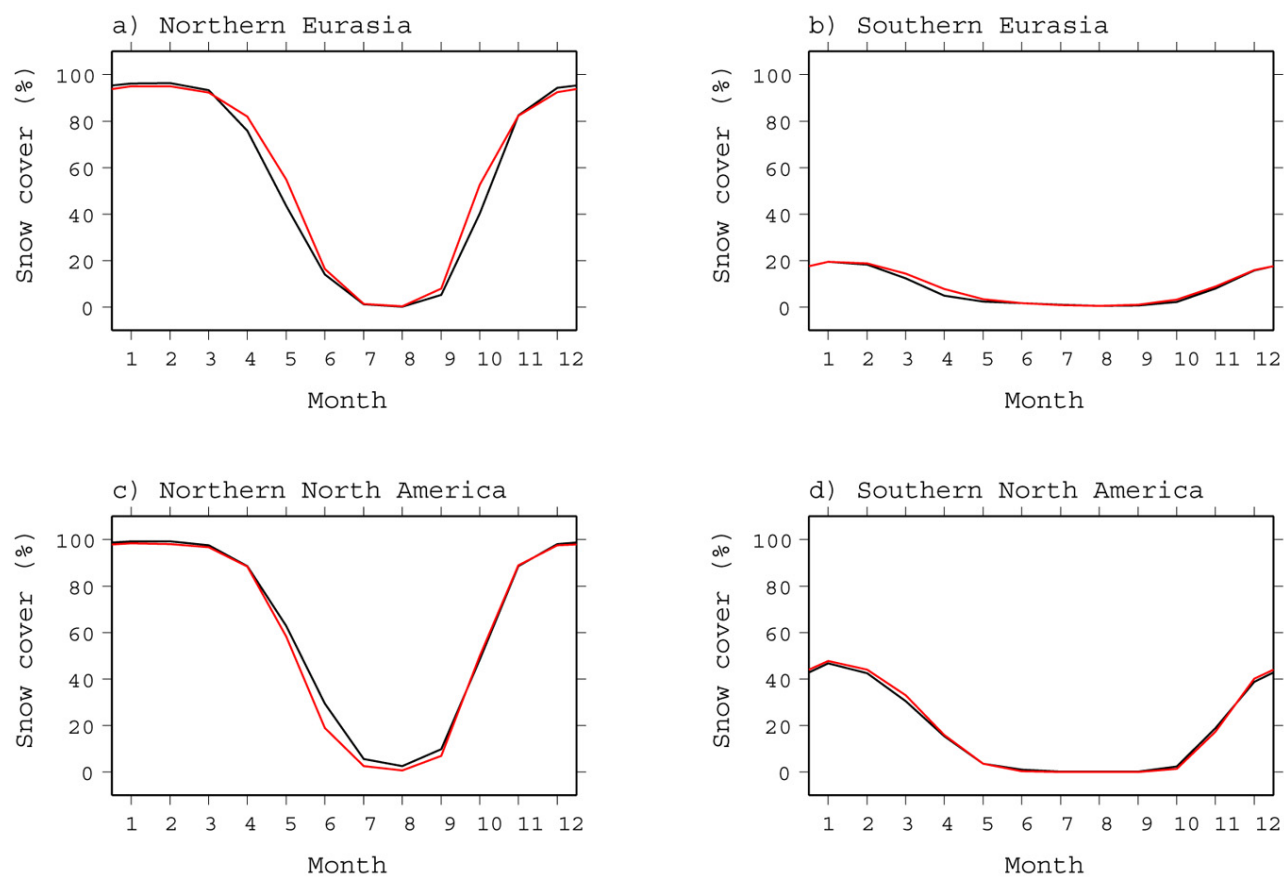

Fig. 2. Seasonal cycles of observed (black) and simulated (red) multi-model mean snow cover for southern (latitude $<50^{\circ} \mathrm{N}$ ) and northern (latitude $\geq 50^{\circ} \mathrm{N}$ ) Eurasia and North America, average over the 1979-2005 period.

bound of the 1 uncertainty range of the observed trend) for only 14 simulations out of 113 .

The underestimate of the recent $\mathrm{NH}$-ifl spring snow cover reduction trend is not due to errors in one particular region; rather, the snow cover reduction trend seems to be systematically underestimated all along the southern fringe of the snow-covered area in spring (Fig. 5a and b), except possibly over eastern North America. A particular case is Tibet, where an observed increase in snow cover, linked to tropospheric circulation anomalies (Zhao et al., 2007), is not reproduced by the models either. Among other less obvious causes, this misfit can be due to either a wrong simulation of the temperature trend over the Northern Hemisphere ice-free land during the melting season, or a wrong simulation of the snowfall trend (which is in part of course linked to the temperature trend, because temperature directly determines the partitioning between snowfall and rainfall). Indeed, the recent $\mathrm{NH}$ extratropical March-April land surface air temperature trends are substantially underestimated (see also Fig. $5 \mathrm{c}$ and $\mathrm{d}$ for 1979-2001): the average observed March-April temperature trend on ice-free land north of $50^{\circ} \mathrm{N}$ in the CRUTEM4

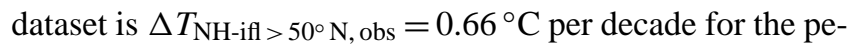
riod $1979-2005\left(0.79^{\circ} \mathrm{C}\right.$ per decade for $\left.1979-2001\right)$, while it is only $\Delta T_{\mathrm{NH} \text {-ifl }>50^{\circ} \mathrm{N} \text {, mod }}=0.38^{\circ} \mathrm{C}$ per decade $\left(0.32^{\circ} \mathrm{C}\right.$ per decade for 1979-2001) in the multi-model mean; less than $20 \%$ of the more than 100 individual model runs exhibit a spring surface air temperature trend $\Delta T_{\mathrm{NH}-\text { ifl }}>50^{\circ} \mathrm{N}$, mod in excess of the observed value of $0.66^{\circ} \mathrm{C}$ per decade. This ob- viously contributes to the underestimate of the spring snow cover trend.

The spatial distribution of snowfall trends (not shown) is difficult to evaluate because the observational data set is rather noisy, certainly because the selected period (1979-2001) is very short. However, average snowfall rates are clearly overestimated in the models: the WATCH dataset suggests an average annual snowfall rate of about $163 \mathrm{~kg} \mathrm{~m}^{-2} \mathrm{yr}^{-1}$ on ice-free land north of $50^{\circ} \mathrm{N}$, while the models simulate an average of $307 \mathrm{~kg} \mathrm{~m}^{-2} \mathrm{yr}^{-1}$. Part of this bias might be explained by inadequate correction of the observed snowfall rates for gauge undercatch (Adam and Lettenmaier, 2003), but this overestimate of snowfall was already noticed for the CMIP3 models (Roesch, 2006). We found no significant correlation between the simulated average snowfall rates and the simulated SCE trends. This means that the overestimate of snowfall does not clearly lead to a reduced sensitivity of snow cover to snowfall decrease, and thus warming, in the models.

\subsubsection{Link between SCE and temperature changes}

As expected for obvious physical reasons, there is a significant relationship between the observed (and simulated) NH-ifl spring snow cover extent and the observed (and simulated) spring surface air temperature over the boreal icefree land areas (Fig. 6a). The simulated and observed temperature sensitivities of the NH-ifl spring SCE are broadly similar. Indeed, the relationship between the observed $\mathrm{NH}$-ifl 
a) Threshold 20 percent

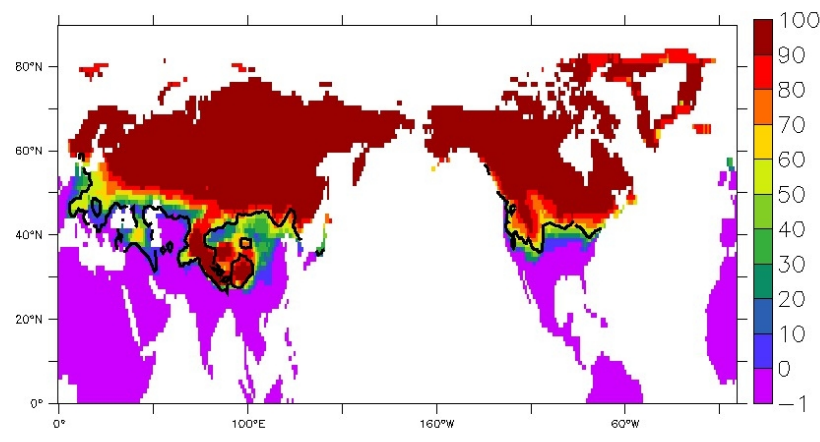

b) Threshold 50 percent

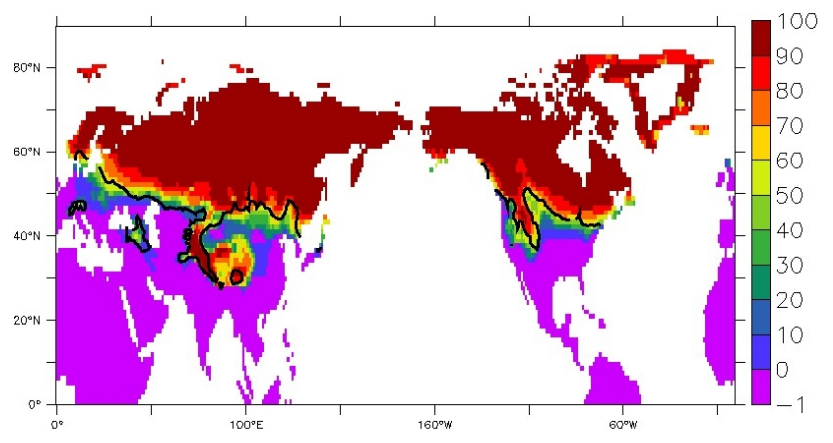

c) Threshold 80 percent

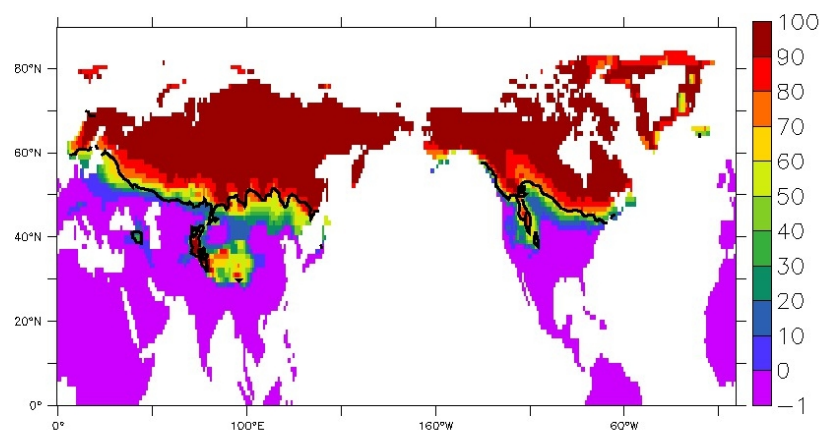

Fig. 3. Percentage of models that simulate a frequency of snow cover in March in excess of a given threshold (shading, in \%), and southern limit of the area where the probability of observing snow cover in march is higher than this threshold (black contour), both for the 1979-2005 period. (a) Threshold 20\%; (b) threshold 50\%; (c) threshold $80 \%$.

spring (March-April) SCE (Brown and Robinson, 2012) and the observed spring surface air temperatures for land areas north of $50^{\circ} \mathrm{N}$ (Jones et al., 2012) is characterized by a slope of $(-3.6 \pm 0.5) \%{ }^{\circ} \mathrm{C}^{-1}$, with $r^{2}=-0.42$ for the $1922-2005$ period (thick black line in Fig. 6a). If the relationship is calculated over the 1979-2005 period, for which the data quality is higher, we find almost the same slope (dashed thick black line in Fig. 6a). For the simulations, the slope between NH-ifl spring SCE and spring surface air temperature of land areas

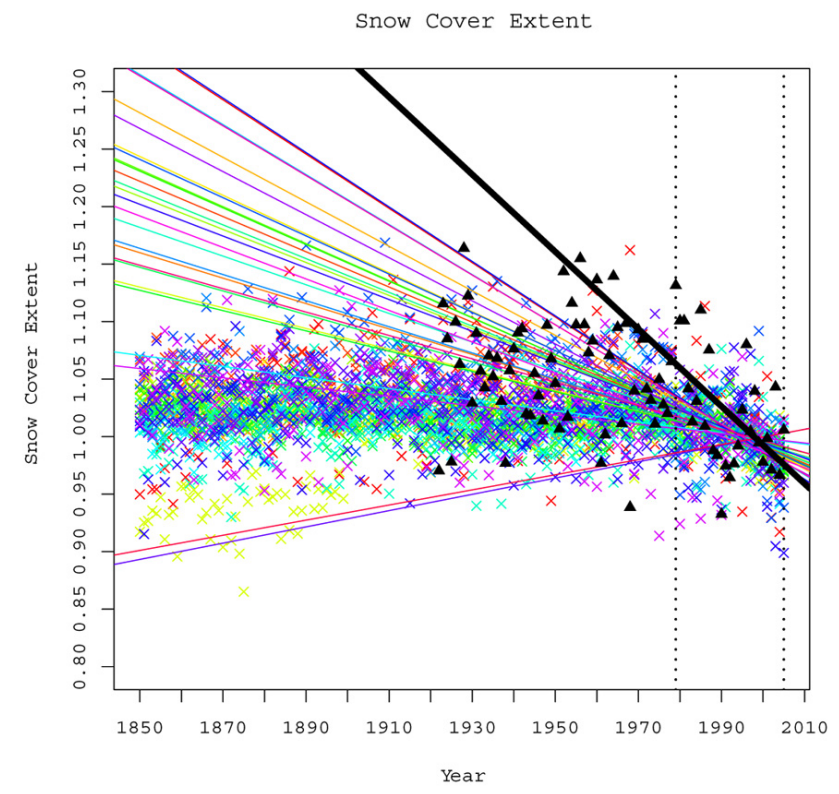

Fig. 4. March-April NH-ifl snow cover extent for the historical CMIP5 simulations of the individual models (colored crosses, normalized with respect to the simulated average 1986-2005 MarchApril extent) and observed March-April snow cover extent (black triangles, normalized with respect to the observed average 19862005 March-April extent). Linear trends are calculated over the 1979-2005 period (black thick line: observed trend, colored lines: individual models). The vertical dotted lines indicate the 1979-2005 period over which the linear trend is calculated.

north of $50^{\circ} \mathrm{N}$ is about $(-2.5 \pm 1.1) \%{ }^{\circ} \mathrm{C}^{-1}$ for the average model, with a spread from -4.3 to $-0.7 \%{ }^{\circ} \mathrm{C}^{-1}$. The simulated and observed relationships between $\mathrm{NH}$-ifl spring surface air temperatures and SCE are therefore consistent within the bounds of uncertainty, although the simulated slope appears a bit weak on average.

As temperature change over the $\mathrm{NH}$-ifl region can be expected to be coherently linked to the global mean annual average temperature change because of climate change pattern scaling (Santer et al., 1999; Mitchell, 2003), we can also expect the $\mathrm{NH}$-ifl spring SCE to exhibit a strong relationship with the annual and global mean temperature, similar to the relationship with $\mathrm{NH}$-ifl spring surface air temperature shown above.

For the observed global annual mean surface air temperatures (Morice et al., 2012) and NH-ifl spring SCE (Brown and Robinson, 2012), this relationship, with a slope of $(-11.8 \pm 2.7) \%{ }^{\circ} \mathrm{C}^{-1}$, is rather noisy $(r=-0.44$ for the 1922-2005 period; thick black line in Fig. 6b), in particular because of a strong interannual variability of SCE, which, as stated before, is underestimated by the CMIP5 models. This observed sensitivity of the NH-ifl spring SCE to global mean temperature change is substantially stronger than the average model sensitivity, which is about $(-5.1 \pm 3.0) \%{ }^{\circ} \mathrm{C}^{-1}$ with a spread from -12.4 to $-0.9 \%{ }^{\circ} \mathrm{C}^{-1}$. The observed 
Table 1. CMIP5 models, groups and acronyms (see http://cmip-pcmdi.llnl.gov/cmip5/).

\begin{tabular}{|c|c|c|}
\hline Modeling Center (or Group) & Institute ID & Model Name \\
\hline $\begin{array}{l}\text { Commonwealth Scientific and Industrial Research Organization } \\
\text { (CSIRO) and Bureau of Meteorology (BOM), Australia }\end{array}$ & CSIRO-BOM & ACCESS1.0 \\
\hline Beijing Climate Center, China Meteorological Administration & $\mathrm{BCC}$ & BCC-CSM1.1 \\
\hline Canadian Centre for Climate Modelling and Analysis & CCCMA & CanESM2 \\
\hline National Center for Atmospheric Research & NCAR & CCSM4 \\
\hline $\begin{array}{l}\text { Centre National de Recherches Météorologiques/Centre Européen } \\
\text { de Recherche et Formation Avancée en Calcul Scientifique }\end{array}$ & CNRM-CERFACS & CNRM-CM5 \\
\hline $\begin{array}{l}\text { Commonwealth Scientific and Industrial Research Organization } \\
\text { in collaboration with Queensland Climate Change Centre of Excellence }\end{array}$ & CSIRO-QCCCE & CSIRO-Mk3.6.0 \\
\hline $\begin{array}{l}\text { LASG, Institute of Atmospheric Physics, Chinese Academy } \\
\text { of Sciences and CESS,Tsinghua University }\end{array}$ & LASG-CESS & FGOALS-g2 \\
\hline NASA Goddard Institute for Space Studies & NASA GISS & GISS-E2-H GISS-E2-R \\
\hline Met Office Hadley Centre & $\mathrm{MOHC}$ & $\begin{array}{l}\text { HadCM3 HadGEM2-CC } \\
\text { HadGEM2-ES }\end{array}$ \\
\hline Institute for Numerical Mathematics & INM & INM-CM4 \\
\hline $\begin{array}{l}\text { Japan Agency for Marine-Earth Science and Technology, } \\
\text { Atmosphere and Ocean Research Institute (The University } \\
\text { of Tokyo), and National Institute for Environmental Studies }\end{array}$ & MIROC & $\begin{array}{l}\text { MIROC-ESM } \\
\text { MIROC-ESM-CHEM }\end{array}$ \\
\hline $\begin{array}{l}\text { Atmosphere and Ocean Research Institute (The University } \\
\text { of Tokyo), National Institute for Environmental Studies, and } \\
\text { Japan Agency for Marine-Earth Science and Technology }\end{array}$ & MIROC & $\begin{array}{l}\text { MIROC4h } \\
\text { MIROC5 }\end{array}$ \\
\hline Max Planck Institute for Meteorology & MPI-M & $\begin{array}{l}\text { MPI-ESM-LR } \\
\text { MPI-ESM-P }\end{array}$ \\
\hline Meteorological Research Institute & MRI & MRI-CGCM3 \\
\hline Norwegian Climate Centre & $\mathrm{NCC}$ & $\begin{array}{l}\text { NorESM1-M } \\
\text { NorESM1-ME }\end{array}$ \\
\hline
\end{tabular}

relationship does not change much if it is only calculated over the 1979-2005 period, for which the data quality is higher (dotted thick black line in Fig. 6b).

This weak sensitivity of the simulated SCE to global annual mean temperature changes is consistent with the fact the NH-ifl temperature trends over the most recent decades are underestimated by the models, while the global mean temperature trends are correctly reproduced. As stated before, the average observed spring (March-April) temperature trend on ice-free land north of $50^{\circ} \mathrm{N}$ in the CRUTEM4 dataset is $\Delta T_{\mathrm{NH}-\mathrm{ifl}}>50^{\circ} \mathrm{N}$, obs $=0.66^{\circ} \mathrm{C}$ per decade, while

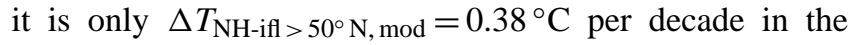
multi-model mean. In contrast, the global and annual average surface air temperature trend simulated over the 1979-2005 period by the available models is $\Delta T_{\text {global, } \bmod }=0.20^{\circ} \mathrm{C}$ per decade, which, given the relatively short time span, compares very well to the HadCRUT4 trend of $\Delta T_{\text {global, obs }}=0.18^{\circ} \mathrm{C}$ per decade. Therefore, the observed boreal (north of $50^{\circ} \mathrm{N}$ ) spring land surface air temperature change amplification

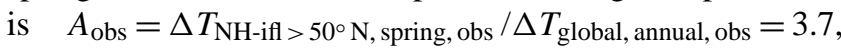
while for the CMIP5 models used here this amplification is $A_{\text {mod }}=1.9$. This translates into an underestimate of the apparent (because not physically direct) sensitivity of $\mathrm{NH}$-ifl spring SCE to global mean temperature changes by the CMIP5 models.

In other words, the direct physical link between local temperature and snow cover appears to be correctly simulated by the models, but the further link between NH-ifl spring SCE and global mean temperature, although it exists both in reality and in the models, is not correctly reproduced because the temperature change amplification on boreal land areas is too weak in the models. A similar underestimate of the boreal land temperature change amplification was also reported for the CMIP3 models (Sutton et al., 2007). There are several reasons for this land/sea warming contrast independent of snow cover. At least in transient climate change, the large 

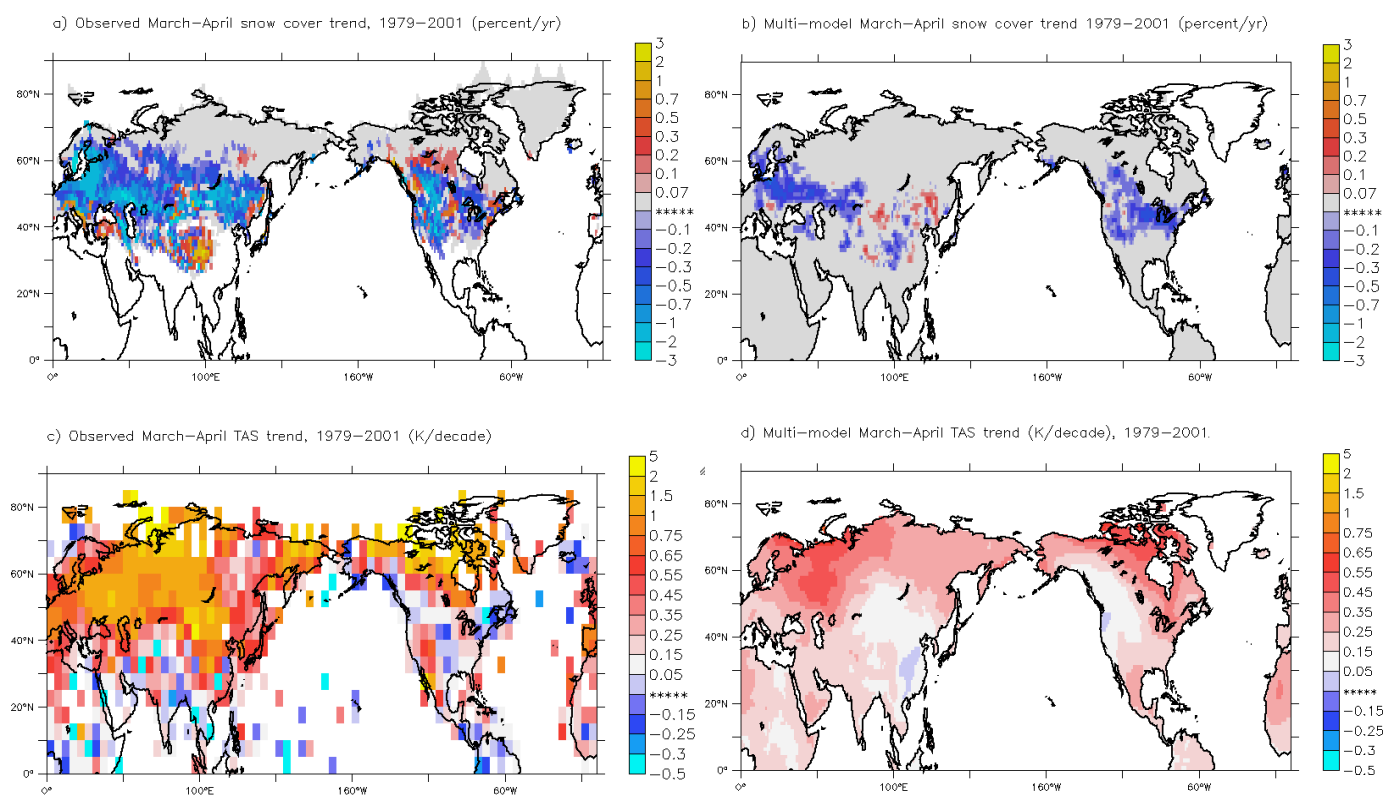

Fig. 5. Observed (left) and simulated (right, multi-model mean) trends of near-surface snow-related variables, for the 1979-2001 period. Top row: March-April average snow cover trend $\left(\% \mathrm{yr}^{-1}\right)$. Bottom row: March-April surface air temperature trend $\left({ }^{\circ} \mathrm{C} / \mathrm{dec}\right.$ ade). Datasets produced by the Rutgers University Global Snow Lab (Robinson and Frey, 2000) are used for observed snow cover, and CRUTEM4 for land surface air temperatures.

thermal inertia of the oceans surely plays an important role (e.g. Hansen et al., 2006). The fact that land areas are drier than ocean surfaces may also cause part of the signal because it means that an additional energy input at the surface is partitioned differently over land and sea: over the ocean, latent surface heat flux will increase more easily than over land, where the drier surface can warm (Sutton et al., 2007). However, it cannot be excluded that over the boreal land areas, part of the underestimated warming might be caused by too weak of a snow-climate feedback in the models. In this context, it is noteworthy that Hall and Qu (2006) report that over boreal land areas, the snow albedo feedback might indeed be underestimated in the majority of the CMIP3 models. There is obviously a strong impact of snow cover on boreal temperatures in spring, as evidenced by Groisman et al. (1994). This can explain part of the recent spring warming over the boreal continents. Therefore, it is possible that an incorrect representation of snow processes is one of the causes of the weak simulated temperature increase over the boreal continents. However, a detailed investigation of the causes of this misfit is beyond the scope of this paper.

\subsection{Climate projections}

\subsubsection{Average SCE, snow mass and trends}

The projected future evolution of the NH seasonal SCE obviously depends very much on the scenario (Fig. 7). For the end of the 21st century (2080-2099), the average reduction of NH-ifl seasonal SCE varies from (7.2 \pm 3.8$) \%$ for RCP2.6 to $(24.7 \pm 7.4) \%$ for RCP8.5, relative to the $1986-2005$ reference period (Table 2). The uncertainty here is given as one inter-model standard deviation, with the ensemble means taken for each individual model before calculating the multimodel means and inter-model variabilities. Over the coming decades, the simulated present trend towards a reduced spring NH snow extent clearly continues in all scenarios, and does not depend on the particular RCP. For the 20162035 period, the models predict a NH-ifl SCE reduction of $5.4 \% \pm 2.0 \%$ for RCP 4.5 , the values ranging from $4.6 \%$ to $6.1 \%$ for the other scenarios with similar inter-model dispersion. The trend starts to level out by about 2030 for the RCP2.6 scenario and accelerates for RCP8.5 without slowing down until the end of the 21 st century. The average simulated SCE trend over the 21 st century under the RCP8.5 scenario (about $-2.5 \%$ per decade) is weaker than the central estimate of the trend observed for the period 1979-2005, but it lies within the uncertainty range $((-3.4 \pm 1.1) \%$ per decade, see Sect. 3.1.1).

\subsubsection{Projected changes as a function of latitude and emission scenarios}

The reduction of snow cover is strongest at the southern limits of the area of seasonal snow cover, where the warming immediately leads to a replacement of solid by liquid precipitation and to earlier melt. This can be clearly seen in Fig. 8, which displays the multi-model average of the zonal mean simulated changes, from the end of the 20th to the 
a)

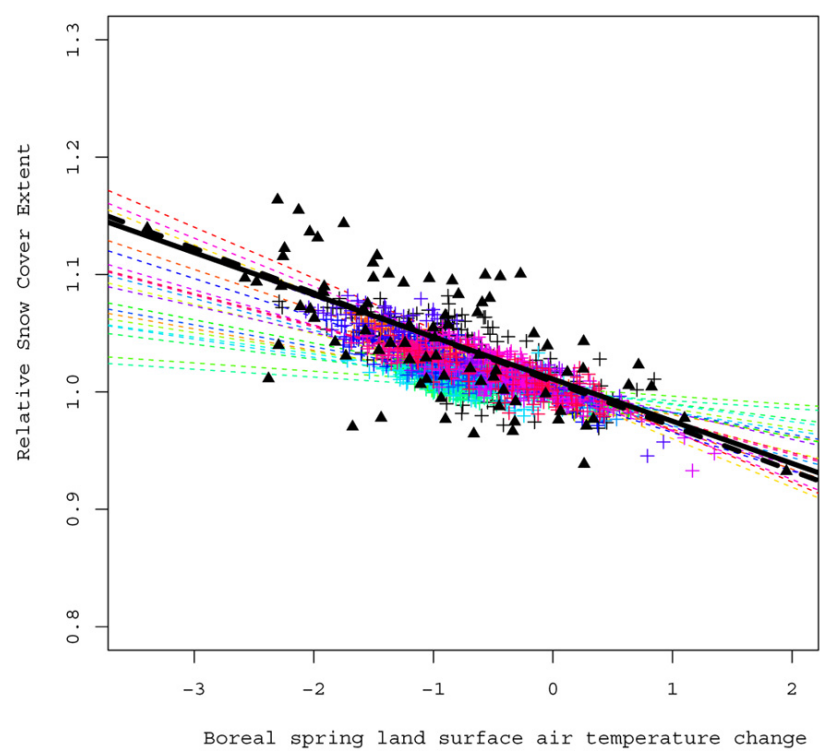

b)

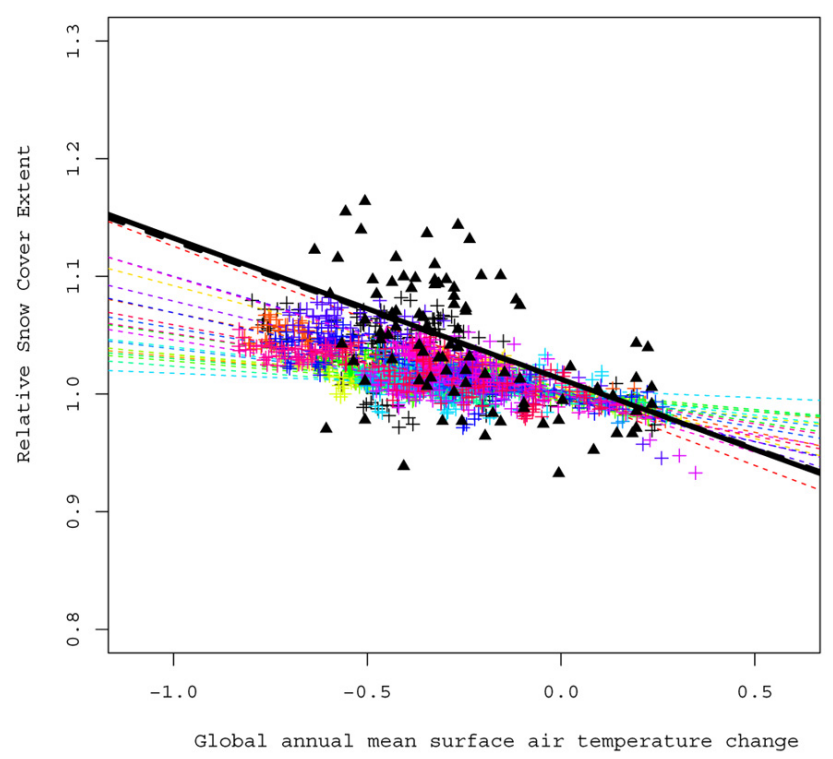

Fig. 6. Observed (black triangles and thick black lines) and simulated (crosses and dashed lines, colors representing the individual models) relationship between the normalized NH-ifl MarchApril SCE (y-axis) and temperature anomalies (x-axis). (a) $\mathrm{x}$-axis: March-April temperature anomalies for land areas north of $50^{\circ} \mathrm{N}$ (CRUTEM4); (b) x-axis: global annual mean temperature anomalies (HadCRUT4). Data and model output are represented for the period 1922-2005. The reference period for temperature and SCE anomalies is 1986-2005. The linear regressions (lines) were calculated for the period 1922-2005, except for the dashed thick line, which shows the regression calculated for the observations over the period 1979-2005.

end of the 21st centuries on ice-free land, of solid precipitation, temperature, annual maximum snow water equiva-
Table 2. Northern Hemisphere ice-free land (NH-ifl) seasonal snow cover change (in $\%, \pm 1 \sigma$ inter-model spread) relative to 1986 2005 , for the four RCPs (march-april average). The number of models taken in account in each scenario is given in parentheses after the scenario name.

\begin{tabular}{lrrrr}
\hline Scenario & RCP2.6 (15) & RCP4.5 (22) & RCP6.0 (12) & RCP8.5 (19) \\
\hline $2016-2035$ & $-5.6 \pm 2.3$ & $-5.4 \pm 2.0$ & $-4.6 \pm 1.6$ & $-6.1 \pm 2.4$ \\
$2080-2099$ & $-7.2 \pm 3.8$ & $-12.9 \pm 4.2$ & $-15.2 \pm 5.8$ & $-24.7 \pm 7.4$ \\
\hline
\end{tabular}

lent and snow season length as a function of latitude for the four RCPs. For all RCPs, the simulated solid precipitation amounts decrease most strongly at low latitudes and increase polewards of about $75^{\circ} \mathrm{N}$ (Fig. 8a). The strong similarity between the four curves, with an approximate rotational symmetry at $75^{\circ} \mathrm{N}$ where the simulated relative solid precipitation change is close to 0 , is obviously due to precipitation change pattern scaling: the basic spatial patterns of solid precipitation change are the same for all four RCPs. The increasing intensity of climate change from RCP2.6 to RCP8.5 translates into an increasingly steep relationship between solid precipitation change and latitude. This is very coherent with Räisänen (2008), who reported a snowfall increase for the CMIP3 climate projections in the high northern latitudes, and it is coherent with observations of snowfall increase in these areas linked to very recent sea ice cover reduction (Liu et al., 2012).

Pattern scaling is equally obvious in the dependency of surface air temperature change as a function of latitude (Fig. 8b), with a clear and coherent signature of polar amplification for all RCPs, again coherent with the CMIP3 models (Masson-Delmotte et al., 2006). As a consequence of the strong snowfall reduction at the more southerly latitudes, the relative reduction of the maximum snow mass is strongest at these latitudes, while the changes are weak further north in spite of stronger warming (Fig. 8c). The relative reduction of snow season length (not shown) is similar: strong at lower latitude and fairly weak at higher latitudes. This is somehow misleading, however: the average snow season length at low latitudes is of course very short, while snow cover is almost permanent close to the pole. For a given scenario, the average change of snow season length in months (Fig. 8d) does not depend very strongly on the latitude in the extratropics. For the latitude bands north of $40^{\circ} \mathrm{N}$, the reduction of the snow season length is roughly about 1.5 months in RCP8.5, while it is less than half a month in RCP2.6. At lower latitudes, the reduction of snow season length is weak for any scenario, simply because the average snow season is already very short at present. The shape of the curves in Fig. 8d is a result of the combined effects of the temperature and snowfall changes, leading to a stronger snow season length shortening in the $50-60^{\circ} \mathrm{N}$ latitude band than further north. 


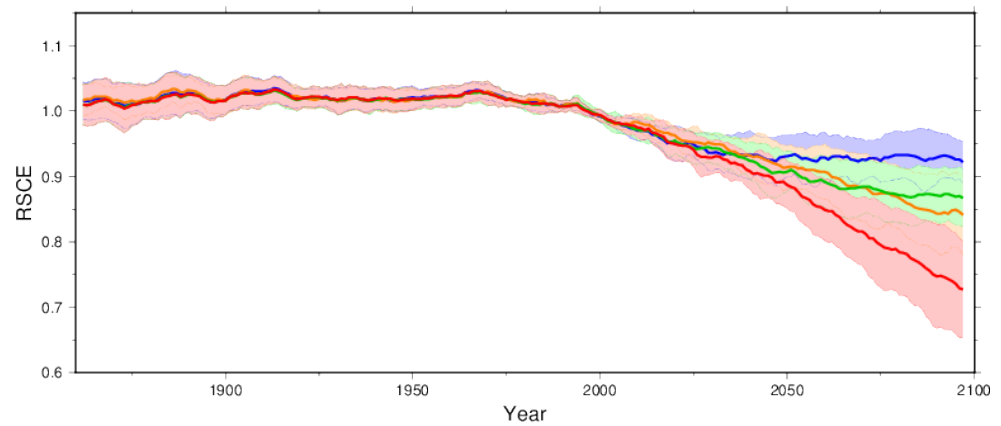

Fig. 7. Projected NH March-April average seasonal snow cover extent (RSCE, relative to the 1986-2005 reference period) for the different RCP scenarios (blue: RCP2.6; green: RCP4.5; yellow: RCP6.0; red: RCP8.5), multi-model average over all available models for each scenario. The 5-yr running average ensemble mean is taken for each individual model before the multi-model average is calculated. Intermodel spread is represented as plus or minus one standard deviation from the multi-model mean.

\subsubsection{Link between projected SCE and future global temperature changes until 2100}

The link between the simulated NH-ifl spring snow cover extent and the simulated global mean temperature shown before (Sect. 3.1.2 and Fig. 6) becomes extremely clear when the model results from the scenario runs until 2100 are also taken into account. The regression lines between NH-ifl spring (March and April average) ice-free land SCE and the global mean surface air temperature for the different scenario runs and for the historical runs are almost identical, and a very strong linear correlation between the two variables emerges. For clarity, this is shown in Fig. 9a only for one particular model (CCSM4). This temperature-SCE relationship becomes non-linear for RCP8.5 beyond 2100, because land area becomes increasingly smaller and eventually vanishes towards the pole. Since the relationships between the two variables are independent of the scenario for a given model, Fig. 9b is restricted to RCP8.5, but shows the relationship for all available models. The linear regressions for the individual models yield an average slope of $(-6.8 \pm 1.4) \%{ }^{\circ} \mathrm{C}^{-1}$, similar to the model results for the historical runs, but with a much lower inter-model spread; the results are more stable because the range of temperature anomalies over the 21 st century in the RCP8.5 scenario is considerably larger than the corresponding range over the 1922-2005 period in the historical runs. Again, this average model slope is much weaker than the observed temperature sensitivity of spring SCE.

\section{Summary and conclusions}

In many respects, the simulated snow covers in the coupled models used in CMIP3 as analyzed by Roesch (2006) and CMIP5 have similar qualities and deficiencies. The snow cover extent is well reproduced by CMIP5 models for the present, and in particular the annual cycle of snow cover on large scale seems to be better reproduced than in CMIP3, but as in CMIP3, the models simulate too much snow in comparison to observations over China and Mongolia. In spite of the good performance of the "mean model", there is a fairly large inter-model dispersion of spring snow cover extent in some regions. Similar to CMIP3, the amplitude of the 1979-2005 $\mathrm{NH}$-ifl March-April snow cover trend is underestimated by the CMIP5 models compared to the observed negative trend: 111 out of the 113 individual model runs analyzed in this study exhibit a weaker than observed snow cover trend of $(-3.4 \pm 1.1) \%$ per decade. The main reason for this misfit appears to be an underestimate of the boreal land surface warming over that period (Fig. $5 \mathrm{c}$ and d). A future increase of solid precipitation in the high northern latitudes with a concomitant decrease further south, similar to what has been projected by the CMIP3 models (Räisänen, 2008), is also suggested by the CMIP5 models.

There is a clear and physically obvious relationship between $\mathrm{NH}$-ifl spring snow cover extent and the spring land surface air temperature north of $50^{\circ} \mathrm{N}$; the sensitivity of $\mathrm{NH}-$ ifl spring SCE to these temperature changes over the 1922 2005 period is reasonably well represented by the models. However, because of an underestimate of the boreal spring land temperature change amplification with respect to the global mean temperature change, the apparent sensitivity of $\mathrm{NH}$-ifl spring SCE to global mean temperature changes is too weak (about $-5{ }^{\circ} \mathrm{C}^{-1}$ instead of about $-12 \%{ }^{\circ} \mathrm{C}^{-1}$ ). One might speculate that this underestimate of the boreal land temperature change amplification might in turn be partially caused by an inadequate representation of snow processes (and therefore of associated feedbacks) in the models. However, we did not notice any obvious relationship between the complexity of the snow models and the simulated boreal land temperature change amplification. In addition, Wallace et al. (2012) have recently shown that the observed strong cold season (November-April) warming over the northern extratropical continents was mainly induced by unforced variability. In any case, this underestimate of the high-latitude continental amplification might be important 
a )
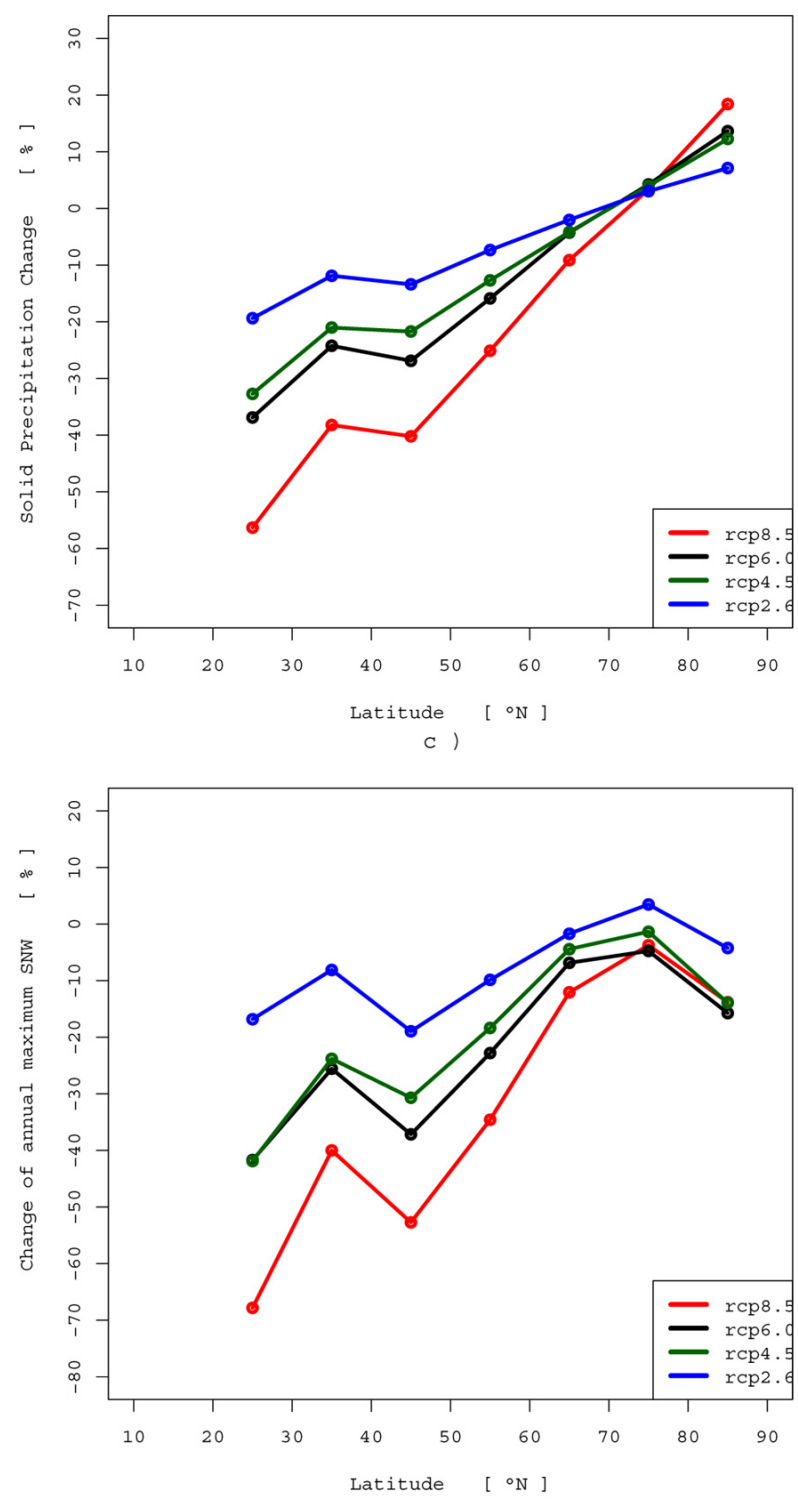

b )
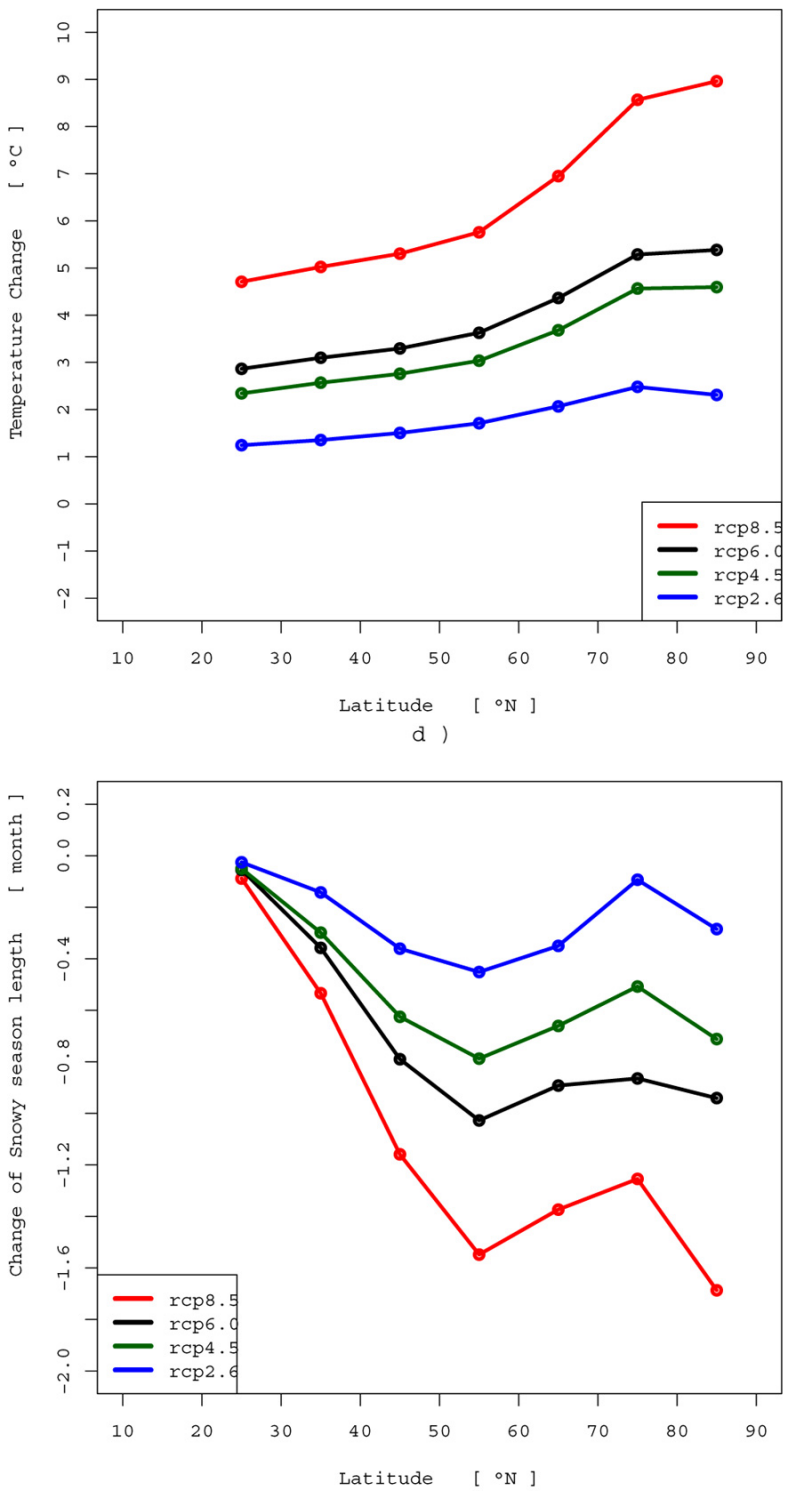

Fig. 8. Zonal mean multi-model mean simulated changes, from the end of the 20th to the end of the 21st centuries, of (a) solid precipitation, (b) temperature, (c) annual maximum snow water equivalent and (d) snow season length for continental grid points as a function of latitude $\left(10^{\circ}\right.$ latitude bands centered at $25,35,45,55,65,75$, and $\left.85^{\circ} \mathrm{N}\right)$ for the four RCPs.

because several potentially major climate feedbacks occur over the boreal land areas. Besides the snow-albedo feedback, greenhouse gas emissions from thawing permafrost (bearing large amounts of organic carbon) might constitute an important feedback to global climate change (e.g. Koven et al., 2011). If the temperature change over boreal land areas is too weak in the coupled climate models, the amplitude of these feedbacks might also be underestimated.

The simulated relationship between NH-ifl SCE and (global or regional) temperature change is similar for the present and for the future scenarios and is in particular independent of the climate forcing scenario. Of course, this lin- ear relationship will eventually break down for extreme climate changes, in which case the southern limit of snow cover could be situated north of the Northern Hemisphere continental realm. However, for plausible climate change scenarios such as the RCPs used in CMIP5 for the 21st century, this linear relationship means that, in principle, future snow cover extent could be expressed in terms of the annual mean global mean temperature. This is useful because annual mean global mean temperature, as the most basic global climate metric, is used in global scientific assessments and as a political target, for example to define thresholds of dangerous human 

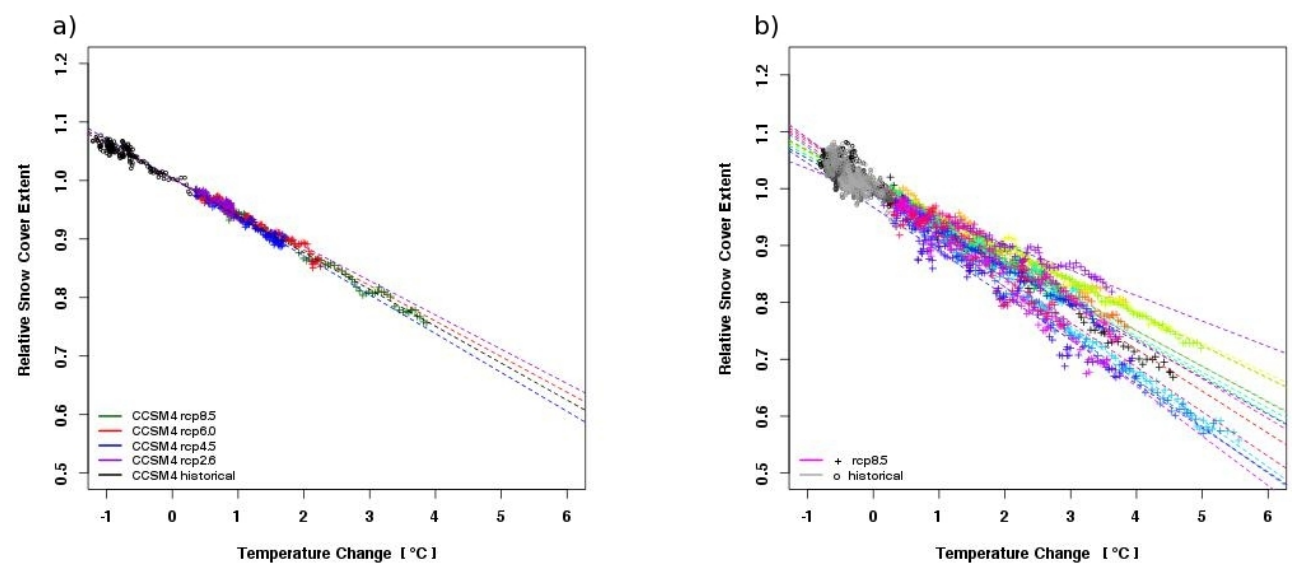

Fig. 9. NH ice-free land spring (March-April) SCE (relative to 1986-2005) as a function of global mean annual mean surface air temperature (relative to 1986-2005), for the historical runs and the scenario runs until 2100. (a) For CCSM4 (4 RCP and historical ensemble means); (b) for all models, RCP8.5 until 2100 and historical ensembles only. The data shown are 5-yr running averages.

interference with the climate system (e.g. Meinshausen et al., 2009).

Acknowledgements. We acknowledge the World Climate Research Programme's Working Group on Coupled Modelling, which is responsible for CMIP, and we thank the climate modeling groups (listed in Table 1 of this paper) for producing and making available their model output. For CMIP, the US Department of Energy's Program for Climate Model Diagnosis and Intercomparison provided coordinating support and led development of software infrastructure in partnership with the Global Organization for Earth System Science Portals. We are grateful to the Rutgers University Global Snow Lab (http://climate.rutgers.edu/snowcover) for making their distributed snow cover data available. This work was supported by Agence Nationale de la Recherche under contracts Paprika and Classique and by funding from the European Union 7th Framework Programme under projects Page21 (grant 282700) and LIFE SNOWCARBO.

Edited by: A. Nolin

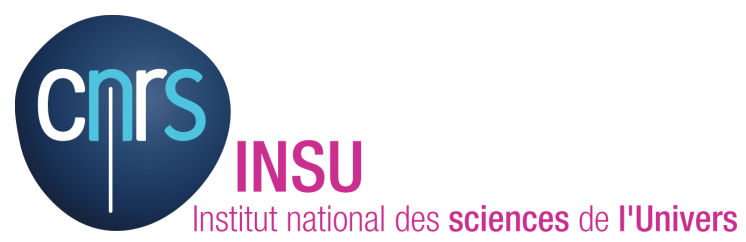

The publication of this article is financed by CNRS-INSU.

\section{References}

Adam, J. C. and Lettenmaier, D. P.: Adjustment of global gridded precipitation for systematic bias, J. Geophys. Res., 108, 4257, doi:10.1029/2002JD002499, 2003.
Alexander, M. A., Tomas, R., Deser, C., and Lawrence, D. M.: The atmospheric response to projected terrestrial snow changes in the late twenty-first century, J. Climate, 23, 6430-6437, doi:10.1175/2010JCLI3899.1, 2010.

Brown, R. D.: Northern Hemisphere snow cover variability and change, 1915-1997. J. Climate, 13, 2339-2355, 2000.

Brown, R. D. and Frei, A.: Comment on "Evaluation of surface albedo and snow cover in AR4 coupled models", edited by: Roesch, A., J. Geophys. Res., 112, D22102, doi:10.1029/2006JD008339, 2007.

Brown, R. D. and Robinson, D. A.: Northern Hemisphere spring snow cover variability and change over 1922-2010 including an assessment of uncertainty, The Cryosphere, 5, 219-229, doi:10.5194/tc-5-219-2011, 2011.

Derksen, C. and Brown, R.: Spring snow cover extent reductions in the 2008-2012 period exceeding climate model projections, Geophys. Res. Lett., 39, L19504, doi:10.1029/2012GL053387, 2012.

Déry, S. J. and Brown, R. D.: Recent Northern Hemisphere snow cover extent trends and implications for the snow-albedo feedback, Geophys. Res. Lett., 34, L22504, doi:10.1029/2007GL031474,2007.

Dewey, K. F.: Daily maximum and minimum temperature forecasts and the influence of snow cover, Mon. Weather Rev., 105, 1594 1597, 1977.

Dye, D.: Variability and trends in the annual snow cover cycle in Northern Hemisphere snow cover areas, 1972-2000, Hydrol. Processes, 16, 3065-3077, 2002.

Fletcher, C. G., Zhao, H., Kushner, P. J., and Fernandez, R.: Using models and satellite observations to evaluate the strength of snow albedo feedback, J. Geophys. Res., 117, D11117, doi:10.1029/2012JD017724, 2012.

Gleckler, P. J., Taylor, K. E., and Doutriaux, C.: Performance metrics for climat models, J. Geophys. Res., 113, D06104, doi:10.1029/2007JD008972, 2008.

Groisman, P. Y., Karl, T. R., and Knight, R. W.: Observed impact of snow cover on the heat balance and the rise of continental spring temperatures, Science, 263, 198-200, 1994. 
Gouttevin, I., Menegoz, M., Dominé, F., Krinner, G., Koven, C., Ciais, P., Tarnocai, C., and Boike, J.: How the insulating properties of snow affect soil carbon distribution in the continental pan-Arctic area, J. Geophys. Res., 117, G02020, doi:10.5194/tc6-407-2012, 2012.

Hall, A. and Qu, X.: Using the current seasonal cycle to constrain snow albedo feedback in future climate change, Geophys. Res. Lett., 33, L03502, doi:10.1029/2005GL025127, 2006.

Hansen, J., Saito, M., Ruedy, R., Lo, K., Lea, D. W., and MedinaElizade, M.: Global temperature change, Proc. Nat. Acad. Sci. USA, 103, 14288-14293, 2006.

Hourdin, F., Issartel, J.-P., Cabrit, B., and Idelkadi, A.: Reciprocity of atmospheric transport of trace species, C. R. Acad. Sci., 329, 623-628, 1999.

Jones, P. D., Lister, D. H., Osborn, T. J., Harpham, C., Salmon, M., and Morice, C. P.: Hemispheric and large-scale land surface air temperature variations: An extensive revision and an update to 2010, J. Geophys. Res., 117, D05127, doi:10.1029/2011JD017139, 2012.

Koven, C. D., Ringeval, B., Friedlingstein, P., Ciais, P., Cadule, P., Khvorostyanov, D., Krinner, G., and Tarnocai, C.: Permafrost carbon-climate feedbacks accelerate global warming, Proc. Nat. Acad. Sci. USA, 108, 14769-14774, 2011.

Krinner, G., Viovy, N., de Noblet-Ducoudré, N., Ogée, J., Polcher, J., Friedlingstein, P., Ciais, P., Sitch, S., and Prentice, I. C.: A dynamic global vegetation model for studies of the coupled atmosphere-biosphere system, Global Biogeochem. Cy., 19, GB1015, doi:10.1029/2003GB002199, 2005.

Lawrence, D. M. and Slater, A. G.: The contribution of snow condition trends to future ground climate, Clim. Dyn., 34, 969-981, 2010.

Lemke, P., Ren, J., Alley, R. B., Allison, I., Carrasco, J., Flato, G., Fujii, Y., Kaser, G., Mote, P., Thomas, R. H., and Zhang, T.: Observations: Changes in Snow, Ice and Frozen Ground, in: Climate Change 2007: The Physical Science Basis, Contribution of Working Group I to the Fourth Assessment Report of the Intergovernmental Panel on Climate Change, edited by: Solomon, S., Qin, D., Manning, M., Chen, Z., Marquis ,M., Averyt, K. B., Tignor, M., and Miller, H. L., Cambridge University Press, Cambridge, United Kingdom and New York, NY, USA, 337-383, 2007.

Liu, J., Curry, J. A., Wang, H., Song, M., and Horton, R. M.: Impact of declining Arctic sea ice on winter snowfall, Proc. Nat. Acad. Sci., 109, 4074-4079, 2012.

Mahlstein, I. and Knutti, R.: September Arctic sea ice predicted to disappear near 2C global warming above present, J. Geophys. Res., 117, D06104, doi:10.1029/2011JD016709, 2012.

Masson-Delmotte, V., Kageyama, M., Braconnot, P., Charbit, S., Krinner, G., Ritz, C., Guilyardi, E., Jouzel, J., Abe-Ouchi, A., Crucifix, M., Gladstone, R. M., Hewitt, C. D., Kitoh, A., LeGrande, A. N., Marti, O., Merkel, U., Motoi, T., Ohgaito, R., Otto-Bliesner, B., Peltier, W. R., Ross, I., Valdes, P. J., Vettoretto, G., Weber, S. L., Wolk, F., and Yu, Y.: Past and future polar ampli?cation of climate change: climate model intercomparisons and ice-core constraints, Clim. Dyn., 26, 513-529, doi:10.1007/s00382-005-0081-9, 2006.

Meinshausen, M., Meinshausen, N., Hare, W., Raper, S. C. B, Frieler, K., Knutti, R., Frame, D. J., and Allen M. R.: Greenhouse-gas emission targets for limiting global warming to
$2{ }^{\circ} \mathrm{C}$, Nature, 458, 1158-1163, doi:10.1038/nature08017, 2009.

Mitchell, T. D.: Pattern scaling: an examination of the accuracy of the technique for describing future climates, Clim. Change, 60, 217-242, 2003.

Morice, C. P., Kennedy, J. J., Rayner, N. A., and Jones, P. D.: Quantifying uncertainties in global and regional temperature change using an ensemble of observational estimates: The HadCRUT4 data set, J. Geophys. Res., 117, D08101, doi:10.1029/2011JD017187, 2012.

Moss, R. H. , Edmonds, J. A., Hibbard, K. A.,Manning, M. R.,Rose, S. K., van Vuuren, D. P., Carter, T. R., Emori, S., Kainuma, M., Kram, T., Meehl, G. A., Mitchell, J. F. B., Nakicenovic, N., Riahi, K., Smith, S. J., Stouffer, R. J., Thomson, A. M., Weyant, J. P., and Wilbanks, T. J.: The next generation of scenarios for climate change research and assessment, Nature, 463, 747-756, 2010.

New, M., Hulme, M., and Jones, P.: Representing twentieth century space-time climate variability, Part I: Development of a 19611990 mean monthly terrestrial climatology, J. Clim., 12, 829856, 1999.

New, M., Hulme, M., and Jones, P.: Representing twentieth century space-time climate variability, Part II: Development of 19011996 monthly grids of terrestrial surface climate, J. Clim., 13, 2217-2238, 2000.

Robinson, D. A. and Frei, A.: Seasonal variability of northern hemisphere snow extent using visible satellite data, Profes. Geogr., 51, 307-314, 2000.

Räisänen, J.: Warmer Climate: less or more snow?, Clim. Dyn., 30, 307-319, 2008.

Roesch, A.: Evaluation of surface albedo and snow cover in AR4 coupled climate models, J. Geophys. Res., 111, D15111, doi:10.1029/2005JD006473, 2006.

Roesch, A. and Roeckner, E.: Assessment of snow cover and surface albedo in the ECHAM5 general circulation model, J. Clim., 19, 3828-3843, 2006.

Santer, B. D., Wigley, T. M. L., Schlesinger, M. E., and Mitchell, J. F. B.: Developing climate scenarios from equilibrium GCM results, MPI report number 47, Hamburg, 1990.

Schneider, U., Fuchs, T., Meyer-Christoffer, A., and Rudolf, B.: Global precipitation analysis products of the GPCC, Global Precip. Climatol. Cent., Dtsch. Wetterdienst, Offenbach am Main, Germany, 2008.

Sutton, R. T., Dong, B., and Gregory, J. M.: Land/sea warming ratio in response to climate change: IPCC AR4 model results and comparison with observations, Geophys. Res. Lett., 34, L02701, doi:10.1029/2006GL028164, 2007.

Taylor, K. E., Stouffer, R. J., and Meehl, G. A.: An Overview of CMIP5 and the Experiment Design, Bull. Amer. Meteor. Soc., 93, 485-498. doi:10.1175/BAMS-D-11-00094.1, 2012.

Uppala, S. M., Kållberg, P. W., Simmons, A. J., Andrae, U., Bechtold, V. D. C., Fiorino, M., Gibson, J. K., Haseler, J., Hernandez, A., Kelly, G. A., Li, X., Onogi, K., Saarinen, S., Sokka, N., Allan, R. P., Andersson, E., Arpe, K., Balmaseda, M. A., Beljaars, A. C. M., Berg, L. V. D., Bidlot, J., Bormann, N., Caires, S., Chevallier, F., Dethof, A., Dragosavac, M., Fisher, M., Fuentes, M., Hagemann, S., Hólm, E., Hoskins, B. J., Isaksen, L., Janssen, P. A. E. M., Jenne, R., Mcnally, A. P., Mahfouf, J.-F., Morcrette, J.-J., Rayner, N. A., Saunders, R. W., Simon, P., Sterl, A., Trenberth, K. E., Untch, A., Vasiljevic, D., Viterbo, P., and Woollen, J.: The ERA-40 reanalysis, Quart. J. Roy. Meteorol. Soc., 131, 
2961-3012, 2005.

van Vuuren, D. P., Edmonds, J., Kainuma, M., Riahi, K., Thomson, A., Hibbard, K., Hurtt, G. C., Kram, T., Krey, V., Lamarque, J.F., Masui, T., Meinshausen, M., Nakicenovic, N., Smith, S. J., and Rose, S. K.: The representative concentration pathways: an overview, Clim. Change, 109, 5-31, 2011.

Vavrus, S.: The role of terrestrial snow cover in the climate system, Clim. Dyn., 29, 73-88, 2007.

Wallace, J. M., Fu, Q., Smoliak, B. V., Lin, P., and Johanson, C. M.: Simulated versus observed patterns of warming over the extratropical Northern Hemisphere continents during the cold season, Proc. Nat. Acad. Sci. USA, 109, 14337-14342, doi:10.1073/pnas.1204875109, 2012.
Walsh, J. E. and Ross, B.: Sensitivity of 30 day dynamical forecasts to continental snow cover, J. Clim., 1, 739-754, 1988.

Weedon, G. P., Gomes, S., Viterbo, P., Shuttleworth, W. J., Blyth, E., Österle, H., Adam, J. C., Bellouin, N., Boucher, O., and Best, M.: Creation of the WATCH Forcing Data and Its Use to Assess Global and Regional Reference Crop Evaporation over Land during the Twentieth Century, J. Hydrometeor., 12, 823-848, 2011.

Zhang, T.: Influence of the seasonal snow cover on the ground thermal regime: An overview, Rev. Geophys., 43, RG4002, doi:10.1029/2004RG000157, 2005.

Zhao, P., Zhou, Z., and Liu, J.: Variability of Tibetan Spring Snow and Its Associations with the Hemispheric Extratropical Circulation and East Asian Summer Monsoon Rainfall: An Observational Investigation, J. Clim., 20, 3942-3955, 2007. 